\title{
Effects on Word and Sentence Recognition by Auditory Training Using Environmental Sound for Elderly Hearing Impaired
}

\author{
Jeehee Kim', Kyoungwon Lee ${ }^{2}$ \\ ${ }^{1}$ Sungnam Joongwon Starkey Hearing Aid Center, Sungnam, Korea \\ ${ }^{2}$ Department of Audiology, Hallym University of Graduate Studies, Seoul, Korea
}

\author{
환경음을 이용한 청능훈련이 난청 노인의 단어 및 문장인지에 미치는 효과 \\ 김 지 희 $\cdot$ 이 경 원 \\ 스타키보청기 성남중원센터', 한림국제대학원대학교 청각학과 ${ }^{2}$
}

\begin{abstract}
Purpose: The purpose of this study was to determine auditory training effects using environmental sounds for elderly hearing-impaired listeners. Methods: A total of sixteen elderly hearing-impaired listeners with sensorineural hearing loss participated. They all had worn hearing aid for more than two months. A half of the participants $(n=8)$ was designated as auditory training group and the rest was not trained (i.e., non-auditory training group, $n=8$ ). Word recognition score, sentence recognition score, and abbreviated profiles of hearing aid benefit (APHAB) scores were evaluated at both pre- and post-auditory trainings and compared them. The auditory training consisted of 16 sessions ( 2 times per a week for eight weeks) was conducted using 45 environmental sounds. Results: The study resulted that WRS and SRS were increased in quiet and noisy situations and APHAB scores were decreased in all categories for the training group. Conclusion: We confirmed that environmental sounds could be useful for the auditory training tool along with words and sentences.
\end{abstract}

Key Words: Auditory training, Environmental sound, Hearing impaired, Hearing aids, Sensorineural hearing loss.

Received: March 11, 2017 / Revised: April 13, 2017 / Accepted: April 15, 2017

Correspondence: Kyoungwon Lee, Department of Audiology, Hallym University of Graduate Studies, 427 Yeoksam-ro, Gangnam-gu, Seoul 06198, Korea Tel: +82-2-2051-4951 / Fax: +82-2-3453-6618 / E-mail: leekw@hallym.ac.kr

\section{INTRODUCTION}

다양한 이유로 청각손실이 발생하면 보청기의 착용, 인공와 우 시술 등을 통하여 난청인의 의사소통능력의 개선을 기대할 수 있다. 청력손실의 정도가 고심도 이상이거나 너무 낮은 단어 인지도(word recognition score, WRS)를 나타내는 경우, 그리 고 외이가 기형적인 형태가 아니라면 기도 보청기(air conduction hearing aid)의 착용을 통해 난청인의 생심리사회적(biopsychosocial)인 핸디캡을 개선할 수 있다. 그러나 대부분의 난 청인들은 보청기를 착용한 후에도 주변의 다양한 소리를 비롯 하여 회화음을 예전처럼 들을 수 없어서 실망을 하며, 이러한 이유로 보청기를 구입하고도 착용을 거부하거나 실패하는 비 율이 높게 나타나고 있다(Koo et al., 2006). 보청기 착용인에게 최적의 음질을 제공하고 어음의 청취능력을 개선하기 위해서는 2-cc 커플러, 실이측정, 기능이득(functional gain), 음장에서의 어음 인지도 측정 등 다양한 보청기 적합의 확인(verification) 을 통하여 보청기의 이득, 최대 출력 등 전기음향적인 요소의 지속적인 조절이 필요하다. 그리고 보청기를 최적으로 조절하 였음에도 불구하고 보청기 착용인이 일상생활에서의 대화능력 이 저하된다면 청능훈련을 시도할 필요가 있다(Humes et al., 2014).

청능훈련은 여러 가지 이유로 어음인지도가 저하된 난청인의 의사소통능력을 극대화할 수 있는 방법 중의 하나다. Brouns et al.(2011)은 소리에 대한 지각은 뇌의 신경가소성에 기초하며, Morais et al.(2015)은 보청기, 인공와우 등 증폭기의 사용만으 로 어음을 인지하는 데 한계가 있기 때문에 난청인이 보청기, 인 공와우 등의 증폭기를 착용한 후 반복적으로 듣는 연습을 통해 보다 개선된 의사소통능력을 향상시킬 수 있다고 보고하였다. 
청능훈련의 도구로는 일음절어, 이음절어, 문장, 숫자 등의 어음과 환경음 등 다양한 소리를 이용할 수 있다. 청능훈련 방 법으로는 조용한 곳 또는 다양한 소음 상황에서 제시한 두 가 지의 소리가 서로 같은지 또는 다른지를 알아내게 하는 등의 분석적(analytic) 방법, 자연스러운 대화 환경에서 이야기를 하 거나 듣게 하는 등의 종합적(synthetic)인 방법을 사용할 수 있 다(Dillon, 2012). 어음을 이용한 청능훈련의 효과를 살펴보면 Stecker et al.(2006)은 감각신경성난청인을 대상으로 집 또는 훈련실에서 잡음 하에서 음절을 인지하는 훈련을 8 주 간 실시 했을 때 무의미음절(nonsense syllable) 인지도의 개선이 있 었다고 하였다. Burk \& Humes(2008)는 난청 노인을 대상으 로 소음 하에서 단어를 이용한 청능훈련을 12 주간 실시했을 때 단어인지도가 향상되었음을 보고하였다. 그리고 Yeo et al.(2014)은 난청 성인을 대상으로 소음 하에서 문장을 사용하 여 6주간 청능훈련을 실시했을 때 보청기에 대한 만족도와 소 음 하에서의 문장인지도(sentence recognition score, SRS)가 향상되었으며, Kim \& Lee(2010)와 Kwon et al.(2013)은 난청 인을 대상으로 소음 하에서 단음절어, 문장 및 속도가 빠른 문 장을 이용하여 8주간 청능훈련을 실시했을 때 소음 하에서 단 어인지도 및 문장인지도가 향상되었다고 보고하였다. 청능훈련 도구는 어음 외에도 환경음을 이용할 수 있는데, Parkinson et al.(1998)과 Tyler \& Kelsay(1990)는 환경음 인지의 향상은 일 상생활에서 안전함과 편안함을 증가시켜 주어 삶의 질 향상에 도 도움이 될 것으로 결론지었다.

환경음의 지각능력은 어음의 지각능력과 상관관계를 보이며 80 94\%의 높은 환경음 인지도를 가진 피검자가 그렇지 않은 피검자보다 $34 \%$ 정도 높은 어음인지능력을 가짐을 통해 환경음 의 인지와 단어인지도 간의 연관성을 보고한 바 있는데(Reed \& Delhorne, 2005), 이는 복합적인 환경음을 처리하는 과정이 어 음을 지각하는 방법과 공통적인 요인을 포함하고 있기 때문이 다(Shafiro, 2008). 또한 조화구조와 시간적 단서가 어음과 비 슷한 환경음 일수록 높은 인지도를 갖는데, Inverso \& Limb (2010)는 이를 근거로 환경음 인지능력의 향상이 어음인지의 개 선에 미치는 긍정적 상관관계를 밝힌 바 있다. Lee \& Kim (2011)의 연구에서는 환경음을 인지하는 능력이 우수한 난청인 이 우수한 단음절 인지능력을 보였으며, 이는 단어인지도의 평 가에 어려움을 겪는 난청군에게 비언어적 자극음인 환경음를 사용하여 평가할 경우 단어인지도를 신뢰도 있게 예측할 수 있 다고 보고하였다. 환경음 청능훈련에서 사용하는 도구를 살펴 보면 환경음과 음악을 비롯한 비언어적 자극음의 인지능력을 평가하는 non-linguistic sound test (Inverso \& Limb, 2010), 흥미를 유발하여 자발적으로 참여하도록 한 후 유사한 단어, 소 음 하 문장, 환경음 찾기가 포함된 eARena (Sweetow \& Sabes,
2006) 등이 있으며, Shafiro(2008)는 40개의 청능훈련용 환경 음을 개발하였다. 국내의 경우는 Ahn \& Lee(2016)가 청능훈 련에 사용할 수 있는 환경음을 개발하였다.

선행 연구를 종합해 볼 때 환경음의 지각훈련은 어음의 인지 능력을 향상할 수 있으며, 결과적으로 증폭기를 통한 의사소통 능력의 개선과 난청인의 삶의 질 향상에 긍정적인 역할을 기대 할 수 있다. 그러나 국내에서는 난청인을 대상으로 환경음 청능 훈련이 어음인지의 향상에 어느 정도 도움이 될 수 있는지에 대한 연구가 부족한 상태이다. 본 연구에서는 Ahn \& Lee(2016) 가 개발한 환경음을 이용하여 주 2회씩 8주간 청능훈련을 실 시했을 때 청능훈련의 효과를 단어인지도, 문장인지도 그리고 보청기 착용 후 심리음향적 이득을 알아볼 수 있는 Abbreviated Profiles of Hearing Aid Benefit (APHAB) (Cox \& Alexander, 1995) 설문지를 통하여 알아보고자 하였다.

\section{MATERIALS AND METHODS}

\section{연구 대상}

본 연구를 위해 한림국제대학원대학교 생명윤리위원회의 심 사를 필하였으며(심의번호: HUGSAUD743862), 대상자는 육 안 관찰 시 이상소견을 나타내지 않는 감각신경성난청인이며 보청기를 2개월 이상 사용 중인 난청 노인으로 하였다. 대상자 는 환경음을 이용하여 훈련을 받는 훈련그룹(training group, ATG)과 훈련을 받지 않는 비훈련그룹(non-training group, $\mathrm{NTG}$ ) 각각 8명으로 하였다. 훈련그룹의 평균 연령은 76.1세(범 위: 69 82세)로 남자 3명, 여자 5명이었으며, 보청기 착용 기간 은 평균 41.3 개월이었다. 훈련그룹 중 보청기 양이 착용자와 단 측 착용자가 각각 4명이었다. 비훈련그룹의 평균 연령은 73.0 세 (범위: 63 82세)로 남자 6명, 여자 2명이었으며, 보청기 착용 기 간은 평균 37.9 개월이었다. 비훈련그룹 중 양이 착용자는 2 명, 단측 착용자는 6 명이었다. 훈련그룹의 평균 순음역치(pure tone average, PTA)의 평균은 $500,1,000,2,000 \mathrm{~Hz}$ 삼분법 기준으 로 우측 $64.2 \mathrm{~dB} \mathrm{HL}$, 좌측 $61.7 \mathrm{~dB} \mathrm{HL}$ 이었다. 그리고 보청기를 착용한 귀의 평균 단어인지도는 54.7\%(범위; 24 72\%)였다. 비 훈련그룹의 평균 순음역치는 $500,1,000,2,000 \mathrm{~Hz}$ 삼분법 기 준으로 우측 $58.8 \mathrm{~dB} \mathrm{HL}$, 좌측 $54.6 \mathrm{~dB} \mathrm{HL}$ 이었고, 보청기를 착용한 귀의 평균 단어인지도는 $62.0 \%$ (범위; 36 84\%)였다. 보 청기의 평균 착용 기간은 훈련그룹이 41.3개월, 비훈련그룹이 37.9 개월이었다. 훈련그룹과 비훈련그룹의 연령, 성별, 보청기 관련 정보 및 단어인지도 정보는 Table 1 , 기도청력역치는 Table 2에 제시하였다. 
Table 1. Ages, gender, information of hearing aid (side, type, number of channel, experience of use) and WRS

\begin{tabular}{|c|c|c|c|c|c|c|c|}
\hline \multirow{2}{*}{ Subjects } & \multirow{2}{*}{ Age } & \multirow{2}{*}{ Gender } & \multirow{2}{*}{ Ear } & \multicolumn{3}{|c|}{ Hearing aid } & \multirow{2}{*}{ Unaided WRS (\%) } \\
\hline & & & & Type & No. of channel & Experience (months) & \\
\hline \multicolumn{8}{|l|}{ ATG } \\
\hline \multirow[t]{2}{*}{ A1 } & 76 & $\mathrm{~F}$ & Right & CIC & 8 & 2 & 68 \\
\hline & & & Left & $\mathrm{CIC}$ & 8 & & 72 \\
\hline $\mathrm{A} 2$ & 75 & M & Left & CIC & 8 & 100 & 48 \\
\hline $\mathrm{A} 3$ & 77 & $\mathrm{~F}$ & Right & CIC & 6 & 12 & 72 \\
\hline \multirow[t]{2}{*}{$\mathrm{A} 4$} & 80 & M & Right & BTE & 4 & 60 & 28 \\
\hline & & & Left & CIC & 4 & & 60 \\
\hline A5 & 82 & $\mathrm{~F}$ & Right & ITC & 8 & 60 & 48 \\
\hline A6 & 75 & $\mathrm{~F}$ & Left & ITC & 8 & 12 & 64 \\
\hline \multirow[t]{2}{*}{ A7 } & 75 & M & Right & CIC & 8 & 36 & 68 \\
\hline & & & Left & $\mathrm{CIC}$ & 8 & & 48 \\
\hline \multirow[t]{2}{*}{ A8 } & 69 & $\mathrm{~F}$ & Right & CIC & 8 & 48 & 56 \\
\hline & & & Left & CIC & 8 & & 24 \\
\hline Mean & 76.1 & & & & & 41.3 & 54.7 \\
\hline \multicolumn{8}{|l|}{ NTG } \\
\hline \multirow[t]{2}{*}{ N1 } & 82 & $\mathrm{~F}$ & Right & CIC & 8 & 36 & 76 \\
\hline & & & Left & CIC & 8 & & 76 \\
\hline $\mathrm{N} 2$ & 65 & M & Right & CIC & 8 & 12 & 84 \\
\hline N3 & 70 & M & Left & CIC & 8 & 60 & 36 \\
\hline N4 & 80 & $\mathrm{~F}$ & Left & ITC & 6 & 60 & 48 \\
\hline \multirow[t]{2}{*}{ N5 } & 77 & M & Right & CIC & 6 & 72 & 60 \\
\hline & & & Left & $\mathrm{CIC}$ & 6 & & 60 \\
\hline N6 & 72 & M & Left & CIC & 8 & 15 & 60 \\
\hline N7 & 75 & M & Left & RIC & 8 & 12 & 76 \\
\hline N8 & 63 & M & Left & CIC & 8 & 36 & 44 \\
\hline Mean & 73.0 & & & & & 37.9 & 62.0 \\
\hline
\end{tabular}

ATG: auditory training group, NTG: non-auditory training group, CIC: completely in-the-canal hearing aid, WRS: word recognition score, ITC: in-the-canal, BTE: behind-the-ear, RIC: receiver in-the-ear

\section{검사 장비 및 훈련 도구}

보청기를 착용하지 않은 상태에서의 기도 및 골도청력역치레 벨(hearing threshold level), 단어인지도의 측정은 보정을 실시 한 청력검사기 AA1200 (Interacoustics, Assens, Denmark)과 TDH-39 헤드폰(Interacoustics) 및 B-71 골진동기(Interacoustics)를 사용하였다. 음장에서의 단어인지도와 문장인지도의 측 정은 청력검사기과 보정을 실시한 $4 \mathrm{ohm}$ 스피커(Interacoustics)를 사용하였다. 어음 평가에 사용한 목록은 한국산업표준 일반용 단음절어(KS-MWL-A) (Kim et al., 2008)와 한국산 업표준 일반용 문장(KS-SL-A) (Jang et al., 2008), 그리고 보 청기 착용 전후의 심리음향적 이득 평가 도구는 Cox \& Alexander(1995)의 APHAB를 사용하였다. 어음과 함께 제시한 소 음은 백색잡음(white noise), 보청기의 성능분석은 Affinity 2.0 (Interacoustics)을 사용하였다. 청능훈련은 소음계로 1 분간 측 정했을 때 소음레벨이 $45 \mathrm{~dB}$ LAeq 미만으로 나타나는 조용한 방에서 실시하였고, 훈련 시 제시음은 노트북 컴퓨터(NT270E5J;
Samsung, Suwon, Korea)와 연결한 $4 \mathrm{ohm}$ 의 외부 스피커(LX3000; Canston), 잡음은 상담실 컴퓨터(DM300S3B-B13L; Samsung)와 연결한 $3 \mathrm{ohm}$ 의 외부 스피커(SH86TH-S; LG, Seoul, Korea)를 이용하여 제시하였다. 청능훈련에 사용한 도 구는 주변에서 빈번하게 들을 수 있는 교통수단, 인간의 신체, 동물, 실내외, 악기 등에서 발생하는 소리로 45 종류씩 2세트로 구성한 Ahn \& Lee(2016)의 음원을 사용하였다. 청능훈련 시 음원 간 진폭의 실효치(root-mean squre)가 같게 나타나도록 조절한 후 음원 파일 앞에는 음원의 평균 실효치와 같은 진폭 의 $1,000 \mathrm{~Hz}$ 보정음(calibration tone)을 삽입하여 제시하는 음 원의 강도를 쉽게 조절할 수 있도록 하였다.

\section{청능훈련 방법}

청능훈련은 한 회당 40 분으로 2 회씩 8 주간 총 16 회를 진행 하였고, 훈련의 구성, 절차, 청능훈련의 평가 내용과 방법은 다 음과 같다. 
Table 2. Air conduction threshold level (dB HL) of ATG and NTG at each frequencies in $\mathrm{Hz}$

\begin{tabular}{|c|c|c|c|c|c|c|c|c|c|c|c|c|}
\hline \multirow{2}{*}{ Subjects } & \multicolumn{6}{|c|}{ Right ear } & \multicolumn{6}{|c|}{ Left ear } \\
\hline & 0.25 & 0.5 & $1 \mathrm{k}$ & $2 \mathrm{k}$ & $4 \mathrm{k}$ & $8 \mathrm{k}$ & 0.25 & 0.5 & $1 \mathrm{k}$ & $2 \mathrm{k}$ & $4 \mathrm{k}$ & $8 \mathrm{k}$ \\
\hline \multicolumn{13}{|l|}{ ATG } \\
\hline $\mathrm{A} 1$ & 35 & 50 & 55 & 55 & 55 & 65 & 40 & 45 & 55 & 55 & 60 & 45 \\
\hline $\mathrm{A} 2$ & 75 & 70 & 75 & 85 & - & - & 75 & 65 & 60 & 75 & - & - \\
\hline A3 & 55 & 40 & 40 & 50 & 65 & 90 & 50 & 35 & 25 & 50 & 70 & 70 \\
\hline A4 & 95 & 75 & 70 & 60 & 70 & - & 80 & 65 & 80 & 60 & 60 & - \\
\hline A5 & 65 & 60 & 65 & 65 & 75 & 80 & 90 & 85 & 75 & 75 & 75 & 90 \\
\hline A6 & 100 & 100 & 100 & 80 & 85 & 90 & 70 & 70 & 65 & 80 & 80 & 85 \\
\hline A7 & 30 & 30 & 40 & 55 & 65 & 55 & 35 & 45 & 55 & 60 & 75 & 65 \\
\hline A8 & 70 & 70 & 70 & 75 & 80 & 90 & 75 & 80 & 60 & 60 & 80 & 90 \\
\hline \multicolumn{13}{|l|}{ NTG } \\
\hline N1 & 45 & 40 & 50 & 50 & 30 & 35 & 50 & 45 & 45 & 50 & 45 & 55 \\
\hline $\mathrm{N} 2$ & 55 & 50 & 55 & 60 & 65 & 85 & 80 & 75 & 80 & 90 & 90 & - \\
\hline $\mathrm{N} 3$ & 60 & 55 & 55 & 60 & 90 & 80 & 75 & 70 & 60 & 65 & 80 & 60 \\
\hline $\mathrm{N} 4$ & 80 & 70 & 80 & 80 & 80 & - & 45 & 35 & 50 & 55 & 65 & 80 \\
\hline N5 & 45 & 60 & 55 & 60 & 65 & 70 & 40 & 65 & 60 & 70 & 80 & 85 \\
\hline N6 & 60 & 60 & 65 & 65 & 90 & - & 30 & 35 & 40 & 45 & 60 & 60 \\
\hline N7 & 60 & 55 & 60 & 70 & 65 & 60 & 45 & 45 & 45 & 50 & 60 & 50 \\
\hline N8 & 55 & 45 & 45 & 65 & 65 & 60 & 50 & 40 & 40 & 55 & 65 & 60 \\
\hline
\end{tabular}

ATG: auditory training group, NTG: non-auditory training group

Table 3. Organization of auditory training using environmental sound

\begin{tabular}{cccc}
\hline Substance & Analyzing & Counselling & Auditory training \\
\hline Time (minutes) & 10 & 10 & 20 \\
\hline
\end{tabular}

\section{청능훈련의 구성}

매 시간별 재활 순서는 먼저 성능분석 10 분, 상담 10 분, 재활 20 분으로, 총 40 분 정도 소요되었으며, 상담 시에는 지난주 보 청기의 상태, 특별한 일정이나 컨디션 등을 문의하였다(Table 3).

\section{청능훈련의 절차}

1 4주차는 환경음 그림 자료를 활용하여 11 개 단위로 환경 음을 들은 뒤 그림판에 인지한 환경음을 붙이게 하였으며, 틀 린 환경음에 대해서는 정답을 알 수 있도록 하였다. 5 6주차에 서는 그림판을 보여주지 않고 제시하여 맞추게 하였으며, 틀릴 경우 정답을 대상자가 알 수 있도록 하였다. 이때 환경음은 1 $\mathrm{kHz}$ 보정음이 피검자의 위치에서 $70 \pm 3 \mathrm{~dB} \mathrm{SPL}$ 이 되도록 조 절하여 제시하였다. 7 8주에서는 소음을 함께 제시하였다. 이 때 신호대잡음비(signal-to-noise ratio, SNR)는 소음 하에서 개인의 환경음 인지 수행능력에 따라서 $58 \mathrm{~dB} \mathrm{SPL}(12 \mathrm{~dB}$ $\mathrm{SNR}$ ) 또는 $64 \mathrm{~dB} \mathrm{SPL}$ ( $6 \mathrm{~dB} \mathrm{SNR}$ 로 제시하였다. 전반적으로 청능훈련의 절차는 쉬운 상황에서 점차 어려운 상황으로 진행 하였다(Table 4).
Table 4. Procedures for auditory training using environmental sound

\begin{tabular}{ccll}
\hline Weeks & Method & \multicolumn{1}{c}{ SNR } & \multicolumn{1}{c}{ Remarks } \\
\hline $1-4$ & Closed-set & In quiet & Using pictures \\
$5-6$ & Open-set & In quiet & Feedback on correct answer \\
$7-8$ & Open-set & $6-12 \mathrm{~dB}$ SNR & Feedback on correct answer \\
\hline SNR: signal-to-noise ratio &
\end{tabular}

\section{청능훈련의 평가}

청능훈련 효과를 평가하기 위해 Table 3에 제시한 평가를 훈 련그룹과 비훈련그룹을 대상으로 동일한 주차에 시행하였다. 훈련그룹과 비훈련그룹의 평가는 청능훈련 전 사전 평가와 8주 훈련 후 사후평가를 실시하였다. 먼저 훈련그룹의 사전 평가에 서는 순음 기도 및 골도청력역치, 단어인지도, 그리고 보청기를 착용한 상태에서의 증폭역치(aided threshold), 단어인지도, 문 장인지도 및 $\mathrm{APHAB}$ 를 평가하였다. 보청기 착용 후 단어인지 도와 문장인지도는 단음절어와 문장을 조용한 곳과 $6 \mathrm{~dB} \mathrm{SNR}$ 에서 $50 \mathrm{~dB} \mathrm{HL}$ 로 제시하여 측정하였다. 사후 평가에서는 보청 기를 착용한 상태에서의 단어인지도, 문장인지도 및 $\mathrm{APHAB}$ 를 평가하였다. 보청기 착용한 상태에서의 단어인지도와 문장 인지도는 단음절어와 문장을 조용한 곳과 $6 \mathrm{~dB} \mathrm{SNR에서} 50$ $\mathrm{dB} \mathrm{HL}$ 로 제시하여 측정하였다. 비훈련그룹의 평가는 훈련그 
룹과 동일하게 진행하였다. 문장과 단어의 평가는 소음수준 40 $\mathrm{dBA}$ 이하의 방음실에서 외부 스피커를 대상자의 귀와 동일한 높이에서 $1 \mathrm{~m}$ 의 거리에 위치시킨 후 정면 $\left(0^{\circ}\right)$ 에서 소음과 문장, 단음절어를 제시하여 실시하였다(Table 5).

\section{분석 방법}

본 연구에서는 훈련그룹은 훈련 전 사전 평가와 훈련 후 사 후 평가 간 결과에 차이를 보이고 비훈련그룹은 같은 기간에

Table 5. Contents of audiological evaluation at 0 and 8th week

\begin{tabular}{|c|c|}
\hline 0 week & 8 week \\
\hline Air/bone conduction threshold & $\begin{array}{l}\text { Aided WRS at } 50 \mathrm{~dB} H L \\
\text { (Q \& } 6 \mathrm{~dB} \text { SNR) }\end{array}$ \\
\hline WRS & $\begin{array}{l}\text { Aided SRS at } 50 \mathrm{~dB} H L \\
\text { (Q \& } 6 \mathrm{~dB} \text { SNR) }\end{array}$ \\
\hline Aided Threshold & AРНAB \\
\hline \multicolumn{2}{|l|}{$\begin{array}{l}\text { Aided WRS at } 50 \mathrm{~dB} H L \\
(\mathrm{Q} \& 6 \mathrm{~dB} \mathrm{SNR})\end{array}$} \\
\hline \multicolumn{2}{|l|}{$\begin{array}{l}\text { Aided SRS at } 50 \mathrm{~dB} H \mathrm{HL} \\
\text { (Q \& } 6 \mathrm{~dB} \text { SNR) }\end{array}$} \\
\hline APHAB & \\
\hline
\end{tabular}

WRS: word recognition score, SRS: sentence recognition score, Q: quiet, SNR: signal-to-noise ratio, APHAB: abbreviated profiles of hearing aid benefit
따라 결과에 차이가 없는지를 확인하고자 하였다. 본 연구의 표 본 크기가 작음을 고려하여 비모수 검정분석을 실시하였다. 따 라서 윌콕슨 부호순위 검정(Wilcoxon signed rank test)을 통 해 훈련 전후에 따라 비교하였고, 조용한 곳 및 잡음 환경의 단 어인지도, 문장인지도 결과와 $\mathrm{APHAB}$ 결과를 각각의 종속변 수로 하였다. 모든 자료의 분석은 SPSS 17.0 (IBM Corp., Chicago, IL, USA)을 사용하였으며 유의수준 $p<0.05$ 를 기준으 로 하였다.

\section{RESULTS}

\section{청능훈련에 따른 단어인지도의 변화}

Figure $1 \mathrm{~A}$ 에서 알 수 있듯이 청능훈련 전과 후에 측정한 훈 련그룹의 평균 단어인지도는 조용한 곳에서는 $59.0 \%$ 에서 65.0\%(중위수: $56,64 \%, Z=-2.64$ ), $+6 \mathrm{~dB}$ SNR에서는 39.0\% 에서 $49.5 \%$ 로 상승하여 유의미한 차이를 나타냈다(중위수: 50 , $46 \%, Z=-1.98)$. 그러나 Figure $1 \mathrm{~B}$ 에서 사전 및 사후 평가에서 측정한 비훈련그룹의 평균 단어인지도는 조용한 곳에서 63.0, 62.5\%(중위수: $64,60 \%$ ), +6 dB SNR에서 49.0, 49.5\%(중위수: 49, 47.5\%)로 두 가지 상황 모두 단어인지도의 유의미한 차이는 나타나지 않았다.
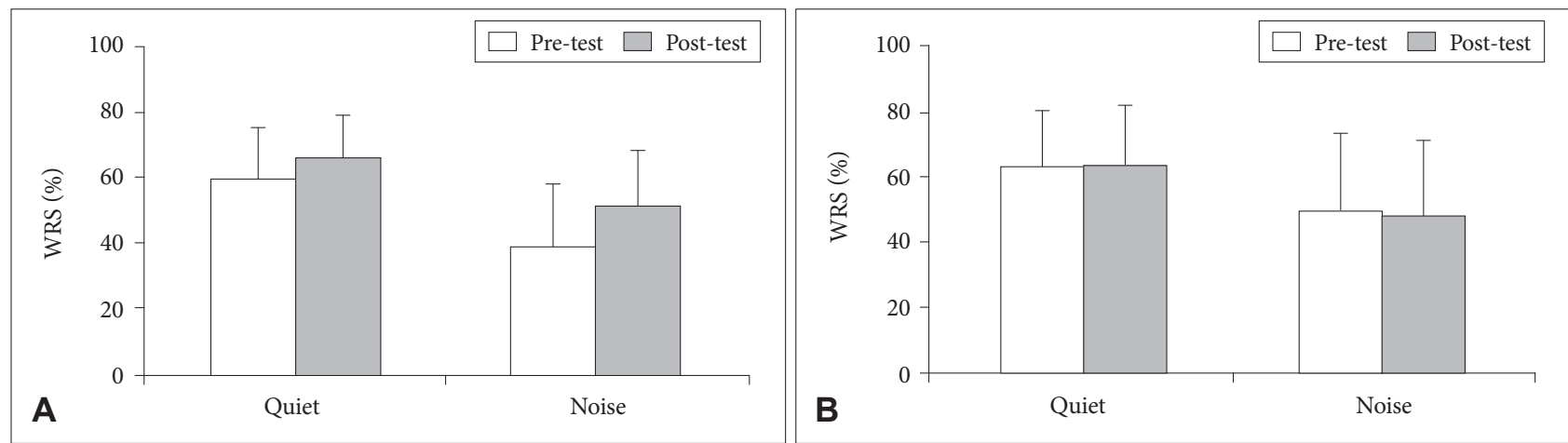

Figure 1. Word recognition scores (WRS) measured in quiet and noisy situation at pre- and post-test. A: Auditory training group. B: Non-auditory training group.
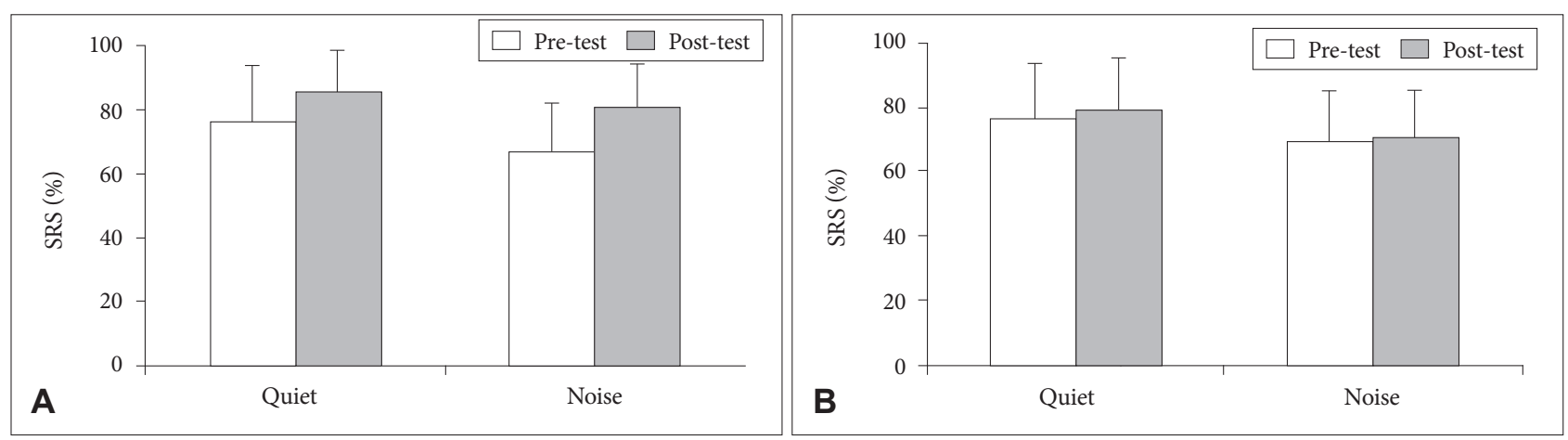

Figure 2. Sentence recognition scores (SRS) measured in quiet and noisy situation at pre- and post-test. A: Auditory training group. B: Nonauditory training group. 


\section{청능훈련에 따른 문장인지도의 변화}

Figure $2 \mathrm{~A}$ 에서 알 수 있듯이 청능훈련 전과 후에 측정한 훈 련그룹의 평균 문장인지도는 조용한 곳에서는 $76.0 \%$ 에서 85.3\%(중위수: $66,82 \%, \mathrm{Z}=-2.38$ ), $+6 \mathrm{~dB}$ SNR 잡음 하에서는 $66.6 \%$ 에서 $80.3 \%$ 로 상승하여 유의미한 차이를 나타냈다(중위 수: $66,82 \%, Z=-2.53)$. 그러나 Figure 2B에서 사전 및 사후 평 가에서 측정한 비훈련그룹의 평균 문장인지도는 조용한 곳에 서 76.6\%와 78.3\%(중위수: 78.5, 78.5\%), $+6 \mathrm{~dB} \mathrm{SNR}$ 에서 $69.4 \%$ 와 70.0\%(중위수: $69.5,68.5 \%$ )로, 두 가지 상황 모두 문 장인지도의 유의미한 차이는 나타나지 않았다.

\section{청능훈련에 따른 $\mathrm{APHAB}$ 의 변화}

Figure $3 \mathrm{~A}$ 에서 알 수 있듯이 훈련그룹의 $\mathrm{APHAB}$ 결과는 easy communication $(\mathrm{EC})$, background noise $(\mathrm{BN})$, reverberation (RV), aversiveness of sound (AV)가 사전 평가에서 각 각 $31.9,53.4,48.4,46.6 \%$ (중위수: $31,59,42.4,49 \%$ ), 사후평가 에서는 각각 $26.8,45.4,39.8,41.6 \%$ (중위수: $26.8,52.9,40.3$, 44.6\%)로 나타나 모든 범주의 점수가 유의미하게 개선되었다(Z $=-2.52,-2.52,-2.52,-2.02, p<0.05)$. 그러나 Figure 3B에서 비훈련그룹의 $\mathrm{APHAB}$ 결과는 $\mathrm{EC}, \mathrm{BN}, \mathrm{RV}, \mathrm{AV}$ 의 평균 점수가 사전 평가에서는 각각 $43.1,50.4,46.8,49.7 \%$, 사후 평가에서는 $43.3,49.2,46.0,50.3 \%$ 로 나타나 모든 범주에서 차이가 나타나 지 않았다.

\section{DISCUSSIONS}

본 연구에서는 보청기를 착용한 감각신경성난청인을 대상으 로 환경음을 이용하여 회당 20분, 주 2회씩 8주간 청능훈련을 실시하였다.

8 주간 청능훈련을 실시하여 사전 및 사후 평가를 비교하면 조용한 곳에서 단어인지도는 $6 \%$, 문장인지도는 $9.3 \%$ 가 증가하 였고, 잡음 하에서는 단어인지도는 $10.5 \%$, 문장인지도는 $13.7 \%$
가 증가하였다. Morais et al.(2015)은 경도난청 노인을 대상으 로 단음절을 이용하여 청능훈련을 시행했을 때 단어인지도가 $9.63 \%$ 향상되어 본 연구와 비슷한 결과를 나타냈다. 국내의 청 능재활 훈련에서 Yeo et al.(2014)은 난청성인을 대상으로 문장 을 이용한 청능훈련 시 단어인지도는 21 39\% 향상되었고 문장 인지도 또한 향상되었다고 보고하였다. 그리고 Kwon et al. (2013)은 난청성인을 대상으로 문장을 이용한 청능훈련에서 단 어인지도와 문장인지도가 $22 \%$ 향상되었다고 보고하여 본 연 구와 차이를 나타냈다. 또한 Burk \& Humes(2008)는 난청성인 을 대상으로 단음절을 이용한 훈련에서 훈련에 사용한 단어인 지도가 $44 \%$ 향상되었다고 하였는데, 이는 청능훈련에서 단음 절을 사용해 평가를 시행하였기 때문이다.

주관적 만족도 평가 도구인 $\mathrm{APHAB}$ 는 $\mathrm{EC}, \mathrm{BN}, \mathrm{RV}, \mathrm{AV}$ 등 의 4 가지 상황의 결과에서 훈련 전 $\mathrm{EC}, \mathrm{BN}, \mathrm{RV}, \mathrm{AV}$ 에서의 불 만족도가 31.9, 53.4, 48.4, 46.6\%였고 훈련 후 동일 범주에서의 불만족도가 $26.8,45.4,39.8,41.6 \%$ 로 감소한 것으로, 분석 결과 평균 $6.6 \%$ 정도 불만족도가 낮아졌음을 알 수 있었다. 선행연 구에서 Yeo et al.(2014)의 APHAB 설문지는 청취 환경적 측면 의 점수가 평균 $8.47 \%$ 개선되었고 Kwon et al.(2013)은 Korean Version of Outcome Inventory for Hearing Aids (K-IOI-HA) (Chu et al., 2012) 설문지를 통해 일상생활의 변화 측정에서 이 익과 삶의 질에 관한 문항이 향상되었는데, 이는 청능훈련이 주 관적 또는 심리음향적 핸디캡의 감소에도 효과가 있었다는 것 을 나타내고 있다. 이는 청능훈련이 주관적 또는 심리음향적 핸 디캡의 감소에도 효과가 있었다는 것을 나타내고 있다.

본 연구에서는 환경음을 이용하여 청능훈련을 실시하였을 때 어음인지도의 변화를 알아보는 연구로, 환경음이 어음과의 연관성이 있음을 알 수 있다. 환경음과 어음 인지에 대한 연구 를 살펴보면 첫째, 소리에 대한 지각은 뇌의 신경가소성에 기초 한다(Brouns et al., 2011). 둘째, 환경음 지각능력은 어음지각능 력과 상관관계를 보이는데, 이는 다소 복합적인 환경음을 처리 하는 과정이 어음을 지각하는 방법과 공통적인 요인을 포함하

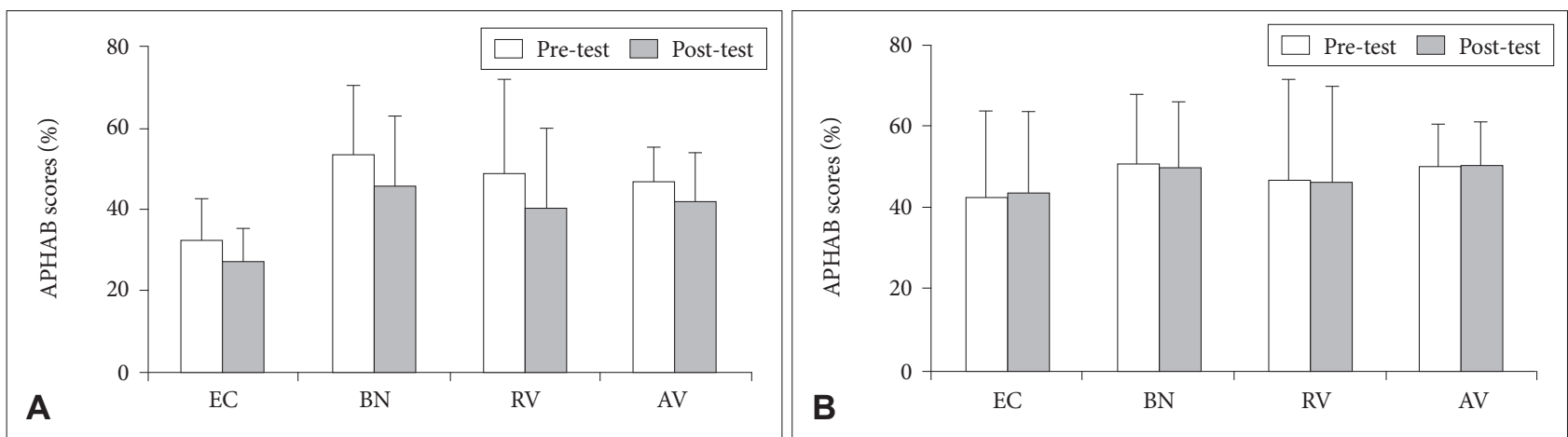

Figure 3. APHAB scores measured at pre- and post test. A: Auditory training group. B: Non-auditory training group. APHAB: abbreviated profiles of hearing aid benefit, EC: easy communication, BN: background noise, RV: reverberation, AV: aversiveness of sound. 
고 있기 때문이라고 하였다(Shafiro et al., 2011). 마지막으로 높은 환경음인지도(80 94\%)를 가진 피검자가 그렇지 않은 피 검자보다 $34 \%$ 정도 높은 어음인지능력을 통해 환경음과 단음 절 인지의 연관성이 있다고 말하고 있어서 본 연구의 환경음 청 능훈련이 어음인지도의 향상에 긍정적인 영향을 끼쳤음을 알 수 있다.

그러나 다른 청능훈련과 훈련의 횟수와 기간을 비교하여 보 았을 때 Yeo et al.(2014)의 경우 주 1회 12주, Kwon et al.(2013) 의 경우 주 1 회 8 주였으나, 본 연구는 주 2 회 8 주, 총 16 회였다. Humes et al.(2014)은 청각 장애 노인에 대한 훈련 도구와 기간 에 따른 청능훈련 효과 연구에서 주 3 회씩 5주 또는 주 2회씩 7.5 주가 가장 효과가 있다고 하였으며, 음성을 도구로 하여 소 음 하에서의 훈련이 가장 효과가 있다고 보고하고 있다. 환경음 에 대한 또 다른 연구에서 Lee \& Kim(2011)은 환경음 주파수 분석 결과 환경음의 에너지가 주로 분포한 주파수를 기준으로 저주파수(250 500 Hz), 중주파수(500 2,000 Hz), 고주파수 $(2,000 \sim 8,000 \mathrm{~Hz})$ 로 나눌 수 있는데, 대부분의 환경음은 넓은 주파수 대역을 보였다고 말하고 있으며 또한 반복되는 패턴이 많은 시간적 정보 특성이 있어 환경음 인지 시 단음절보다 청 자가 사용할 수 있는 정보가 더 풍부하다고 말하고 있다. Gygi et al.(2004)은 건청성인을 대상으로 시간적 포락선(temporal envelope) 특성에 의해 환경음을 인지하는지를 확인한 결과, 주 파수 정보가 제한적일지라도 시간적 정보로 환경음의 인지가 가능했음을 보고하였다. 이는 환경음의 어음인지와 또 다른 특 성을 살펴볼 수 있다. 본 연구에서는 이러한 선행 연구들이 훈 련의 횟수와 강도에 비해 효과가 적게 나타난 요인으로 해석할 수 있다. 또한 조용한 상황보다 잡음 하에서 좀 더 많이 상승하 였다. 단어인지도는 조용한 곳에서 $6 \%$, 잡음 하에서 $10.5 \%$, 문 장인지도는 조용한 곳에서 $9.3 \%$, 잡음 하에서 $13.7 \%$ 증가하였 는데, 이는 앞에서 언급한 소음 속 훈련과 8주간의 계속된 훈 련으로 인한 집중력 향상에서 원인을 찾아볼 수 있다.

본 연구에서 훈련그룹은 단어인지도가 높은 대상자일수록 환경음 또한 잘 인지하였고, 잘 인지하지 못한 환경음은 단음절 과 동일한 소리는 들리는데 무슨 소리인지 구별하기가 힘들다고 하였다. 또한 주파수별 특성에 의해 고주파 대역의 청력역치레 벨이 훈련그룹에서는 매미소리와, 새소리 등을 잘 인지하지 못 하였고 노인을 대상으로 한 훈련이기에 비트박스 소리와 반복 패턴이 없는 지퍼소리, 변기 물 내리는 소리 등은 거의 인지하 지 못하였다. Lee \& Kim(2011)의 연구에서는 난청 기간이 긴 인공와우 착용자가 비교적 저하된 환경음 인지도를 보였는데, 이는 환경음에 대한 청능훈련을 받지 않은 경우 난청 기간이 길수록 환경음에 실제로 노출될 기회가 적어서 인지도 또한 좋 지 않았다고 하였다.
본 연구는 환경음 인지훈련이 어음인지도에 미치는 영향을 보는 훈련으로, 환경음을 이용하여 훈련을 실시한 결과 장기간 계속된 훈련으로 인한 지루함과 피로함을 호소하여 중도에 훈 련을 포기하는 대상자가 있었다. 그리고 대상자가 대부분 노인 이었기 때문에 $\mathrm{APHAB}$ 설문이나 단어인지도 및 문장인지도의 평가에 어려움이 많았다. 따라서 좀 더 신뢰도가 높은 데이터 를 수집하기 위해서는 청년 또는 장년층을 대상으로 한 연구가 필요할 것으로 생각한다.

결론적으로 보청기를 착용한 감각신경성난청인을 대상으로 주 2회씩 8주간의 환경음만을 이용한 청능훈련을 실시했을 때 조용한 곳 및 소음 상황에서 보청기 착용 후의 단어인지도와 문장인지도가 개선되었음을 알 수 있었다. 이는 환경음의 인지 능력이 어음인지에 미치는 긍정적인 역할로 생각할 수 있으며, 향후 단어나 문장으로 훈련이 불가능한 경우에 청능훈련 도구 로 사용할 것으로 기대한다.

중심 단어 : 청능훈련·환경음·난청인·보청기·감각신경성난청.

\section{REFERENCES}

Ahn, P. H. \& Lee, K. (2016). Development of environmental sounds for auditory training. Audiology and Speech Research, 12(2), 82-88.

Brouns, K., El Refaie, A., \& Pryce, H. (2011). Auditory training and adult rehabilitation: A critical review of the evidence. Global Journal of Health Science, 3(1), 49-63.

Burk, M. H. \& Humes, L. E. (2008). Effects of long-term training on aided speech-recognition performance in noise in older adults. Journal of Speech, Language, and Hearing Research, 51(3), 759-771.

Chu, H., Cho, Y. S., Park, S. N., Byun, J. Y., Shin, J. E., Han, G. C., et al. (2012). Standardization for a Korean adaptation of the international outcome inventory for hearing aids: Study of validity and reliability. Korean Journal of Otorhinolaryngology-Head and Neck Surgery, 55(1), 20-25.

Cox, R. M. \& Alexander, G. C. (1995). The abbreviated profile of hearing aid benefit. Ear and Hearing, 16(2), 176-186.

Dillon, H. (2012). Hearing aids. (2nd ed.). (pp. 391-392). New York, NY: Thieme.

Gygi, B., Kidd, G. R., \& Watson, C. S. (2004). Spectral-temporal factors in the identification of environmental sounds. The Journal of the Acoustical Society of America, 115(3), 1252-1265.

Humes, L. E., Kinney, D. L., Brown, S. E., Kiener, A. L., \& Quigley, T. M. (2014). The effects of dosage and duration of auditory training for older adults with hearing impairment. The Journal of the Acoustical Society of America, 136(3), 224-230.

Inverso, Y. \& Limb, C. J. (2010). Cochlear implant-mediated perception of nonlinguistic sounds. Ear and Hearing, 31(4), 505-514.

Jang, H. S., Lee, J. H., Lim, D. H., Lee, K. W., Jeon, A. R., \& Jung, E. J. (2008). Development of Korean standard sentence lists for sentence recognition tests. Audiology, 4(2), 161-177.

Kim, H. \& Lee, K. W. (2010). Effects of word recognition score as a function of auditory training terms for elderly hearing impaired with hearing aid. Audiology, 6(2), 159-163.

Kim, J. S., Lim, D. H., Hong, H. N., Shin, H. W., Lee, K. D., Hong, B. N., et al. (2008). Development of Korean standard monosyllabic word lists for adults (KS-MWL-A). Audiology, 4(2), 126-140.

Koo, S. M., Kim, J. S., \& Lim, D. H. (2006). A summary of the census for the disabled in Korea-focusing on the hearing impaired. Audiology, 
2(1), 52-57.

Kwon, Y., Oh, C. J., Lim, E. H., \& Bahng, J. (2013). Proceedings from 16th Korean Academy of Audiology: Effects of 8-Week Auditory Training: Time Compression Sentences and Sentences in Noise. (pp. 65-69). Daegu: Daegue Catholic University.

Lee, J. H. \& Kim, J. H. (2011). Comparison of word and environmental sound recognition by cochlear implant and hearing aid users. Audiology, 7(1), 28-39.

Morais, A. A., Rocha-Muniz, C. N., \& Schochat, E. (2015). Efficacy of auditory training in elderly subjects. Frontiers in Aging Neuroscience, 7, 78.

Parkinson, A. J., Parkinson, W. S., Tyler, R. S., Lowder, M. W., \& Gantz, B. J. (1998). Speech perception performance in experienced cochlearimplant patients receiving the SPEAK processing strategy in the Nucleus Spectra-22 cochlear implant. Journal of Speech, Language, and Hearing Research, 41(5), 1073-1087.

Reed, C. M. \& Delhorne, L. A. (2005). Reception of environmental sounds through cochlear implants. Ear and Hearing, 26(1), 48-61.

Shafiro, V. (2008). Development of a large-item environmental sound test and the effects of short-term training with spectrally-degraded stimuli. Ear and Hearing, 29(5), 775-790.

Shafiro, V., Gygi, B., Cheng, M. Y., Vachhani, J., \& Mulvey, M. (2011). Perception of environmental sounds by experienced cochlear implant patients. Ear and Hearing, 32(4), 511-523.

Stecker, G. C., Bowman, G. A., Yund, E. W., \& Herron, T. J. (2006). Perceptual training improves syllable identification in new and experienced hearing aid users. Journal of Rehabilitation Research and Development, 43(4), 537-552.

Sweetow, R. W. \& Sabes, J. H. (2006). The need for and development of an adaptive listening and communication enhancement $\left(\mathrm{LACE}^{\mathrm{TM}}\right)$ program. Journal of the American Academy of Audiology, 17(8), 538-558.

Tyler, R. S. \& Kelsay, D. (1990). Advantages and disadvantages reported by some of the better cochlear-implant patients. The American Journal of Otology, 11(4), 282-289.

Yeo, S., Bahng, J., \& Lee, J. H. (2014). Efficacy of auditory training using sentences in noise for hearing aid users. Audiology, 10(1), 65-75. 